\title{
FACTORS INFLUENCING EMPLOYEES' TURNOVER INTENTION IN BANGKOK, THAILAND
}

\author{
Pachoke Lert-Asavapatra
}

Suan Sunandha Rajabhat University, Bangkok, Thailand

The objectives of this research are: 1) to study the personal factors, the level of perceived organizational support factors and the turnover intention of employees in Bangkok; 2) to investigate the relation between personal factors, perceived through organizational support factors that influence employees' turnover intention in Bangkok. The sample consists of 385 respondents employed in Bangkok, and the data was collected by means of using the multi-stage sampling methods. Questionnaires were used as the research instrument. Multiple linear regressions were used to test the hypotheses. The results show that the majority of the respondents in the sample were less than 30 y.o., single, with bachelor's degree and less than 5 years of work experience. The results of the regression analysis indicate that the personal factor of degree and the perceived organizational support (promotion) affect the turnover intention at the 0.05 and 0.01 levels of significance.

Keywords: turnover intention; employees; Bangkok; organizational support; survey; linear regression; factor of education.

\section{Introduction}

Business competition is always highly dependent on the factor of human resource, especially when it comes to qualified personnel. According to the survey carried out by Tower Watson (Tower Watson's Thailand, 2014) in 2014, the highest rate of job losses in Thailand was demonstrated by the industrial sector. Thus, we can make a conclusion that Thai industrial companies are often facing the problem of retaining staff.

In such a context, the key problem with resignations is that personnel with knowledge are leaving mostly, and this, obviously, affects organizations in the most negative way. High turnover of employees is always a burden due to high costs for the organization: the organization has already invested in the professional development of an individual, and once he/she is leaving - these costs are wasted. If the turnover rate is too high, employees' turnover becomes more rewarding for the employees themselves (Boonruam Thai-Prasert, 2010).

Speaking more broadly, this trend can affect the image of the business environment of the whole country. Negative attitudes influence the decision-making on the location of an organization or production facilities to be made by both domestic and foreign investors (Heizer \& Render, 2014).

\section{Pachoke Lert-Asavapatra}

Lecturer in College of Innovation and Management,

Suan Sunandha Rajabhat University, Bangkok, Thailand

Research interests - Innovation, Management, HRM 


\section{FACTORS INFLUENCING EMPLOYEES}

Numerous problems related to employees' turnover have been already explained in both theoretical studies and in applied research. However, in this particular case the researcher is interested in studying the factors influencing the resignation of private employees in Bangkok. In particular, the intention is to study the gender-related factors, personal factors, age and marital status as well as education factors on the working time. Additionally to that, the author plans to study the influence of both monetary reward and non-monetary reward factors on employees. The central question here is which factors are really influencing the willingness of resign in the case of private employees in Bangkok.

\section{Objectives}

- to study the relationship between organizational support and turnover intention of private employees in Bangkok;

- to study the factors that influences the turnover intention of private employees in Bangkok.

\section{Literature review}

Thinknet Co., Ltd. is the company that once launched the website. www.Jobthai.com This is a website that serves as a medium for numerous job seekers in the country. Most of new job applicants in Bangkok as compared to other provinces in Thailand have rather frequent job rotations. The data presented in this study has been collected over a year, the end date being January 1, 2018. The data show that many of such applications are only 1-3 years old. Private employees who are currently leaving their current position will soon be inclined to changing jobs.

Studies on this and the related issues go back to the second half of the previous century. Homo Griffeth (1995, as cited in David G. Allen, 2003) describes the relationship between perceived organizational support and resignation. The author concluded that perceived organizational support (POS) is directly related to job satisfaction and organizational commitment. Both of these variables are related to turnover intentions, thus leading to a certain rate of employees' turnover.

According to David G. Allen (2003), perception of organizational support has a positive influence on job satisfaction and organizational commitment. Job satisfaction and organizational commitment will, in turn, have a negative impact on the willingness to resign. And finally, the willingness to resign will have a positive influence on resignation.

Perception of organizational support affects the intention of the resignation as stated by Talat Islam (2013). The intention to resign due to the influences of perception, organizational support, and engagement with the organization has been well grounded in this study. Talat Islam has offered an own model of resignation so that to study the direct relationship between perceived support and the intention to resign.

The mentioned article studied the influence of perceived organizational support on resignation intentions, namely, direct effect on the intention to resign without the influence of other variables or factors. The results of Talat Islam's study on the relationship between perceived organizational support and the intention to resign directly indicates that organizational support perceptions correlate significantly with the willingness to resign. The level of statistical significance was 0.01 . 
L. Rhoades \& R. Eisenberger (2002) have also studied the perception of organizational support. There are numerous other research findings that can be used to validate the relationship of perceived organizational support with all the HR-related factors and variables. For this reason, the researchers here are interested in perceived organizational support (POS) as one of the key factors contributing to resignation, with the intermediate of some other variables, the level of education, for example.

\section{Methodology}

The research population covers a wide range of private sector organizations.

Offices of all these organizations are located in Bangkok, the capital of Thailand.

The total sample size was 385; the multistage random sampling was applied.

Tools used in this research include: closed-end and open-end questions. The questionnaire was designed to divide all personal factors into two groups: organizational support and the intention to resign.

The reliability of the questionnaire was determined to be at the level of 0.7 .

\section{Results}

General data on the respondents covered the following points: sex, age, marital status, education level and duration of the current employment.

Most of the surveyed individuals were male (276, or $71.7 \%$ ), younger than 30 years old. 232 people (or $60.25 \%$ ) in the sample were single; 280 people (or $72.7 \%$ ) had bachelor degree. The duration of current employment for 208 people $(54.02 \%)$ was no more than 5 years.

The results concerning the mean and the standard deviation of the respondents' responses are shown in Table 1.

Table 1. Results of the standard deviation analysis

( made by co-authors)

\begin{tabular}{|c|c|c|}
\hline Variable & Mean (average) & S.D. \\
\hline Corporate Support Recognition & & \\
\hline Monetary reward & 3.4286 & 0.7270 \\
\hline Non-monetary reward & 3.4768 & 0.70583 \\
\hline Intention to resign & 2.8166 & 0.96056 \\
\hline
\end{tabular}

\section{Conclusions and Discussion}

Analysis here has been carried out to test the relationship between various personal factors. Perception of organizational support and its influence on one's intention to resign were found to be in the following dependence:

1. The level of education correlated with the intention to resign significantly at the 0.05 level. The research result is in accordance with the research conclusion of Pappatchakit Thong (2009) and also that of Elizabeth Medina (2012). 


\section{FACTORS INFLUENCING EMPLOYEES}

2. Recognition of organizational non-monetary support is in the relationship with the willingness to resign significantly at the 0.01 level. This is consistent with Linda Rhoades' results (2002). Thus, we can confirm that organizations should provide more non-monetary compensation to their employees so that to keep them from resigning. Recognition of nonmonetary reward provided by organization is always negatively correlated with the willingness to resign.

\section{Suggestions}

From the findings of this study we can make the following conclusions. Top management and/or human resource departments of organizations should focus more on policies and strategies of becoming a learning organization and/or innovative organization. Internal promotion through personal professional development and life-long education can be used to influence on the factor contributing to the intention to resign. This will also lead to the development of creative solutions to various other problems of employees at all times.

\section{Acknowledgement}

The author would like to thank the Research and Development Institute, Suan Sunandha Rajabhat University, Bangkok, Thailand for financial support.

\section{References:}

Thai-Prasert, B. (2010). Causes and effects of resignation of employees of Multbase Public Company Limited Laem Chabang Industrial Estate Chonburi province. Master Thesis in Public and Private Sector Management. College of Public Administration, Burapa University.

Medina, E. (2012). Job Satisfaction and Employee Turnover Intention: What Does Organizational Culture Have To Do With It? Master of Arts thesis, Columbia University.

Heizer, J. \& Render, B. (2014). Operations Management. The United States of America: Pearson Education, Inc.

Vanichbancha, K. (2012). Statistics for Research. Bangkok: Book Center of Chulalongkorn University.

Rhoades, L. \& Eisenberger, R. (2002). Perceived Organizational Support: A Review of the Literature. Journal of Applied Psychology, 87(4), pp. 698-714.

MGR online. 2016. The most hot '11' branch you need to know. Accessible at: http://www.manager.co.th/campus/ViewNews.aspx?NewsID=9590000020843

Nakjuethong, N. (2009). A study of factors affecting the resignation trend of employees in Rojana Industrial Park. Phra Nakhon Si Ayutthaya Province. Individualized Education Program in Master of Business Administration, College Bangkok University.

Muanderm, P. (2011). Factors affecting the resignation of the employees of Sony Co., Ltd. Master of Business Administration thesis, College Bangkok University.

Tirakanan, S. (2014). Research Methodology in Social Science: A Practical Approach. No. 12. Bangkok: Book Center of Chulalongkorn University.

Tae Heon Lee. (2012). Gender Differences in Voluntary Turnover: Still a Paradox? International Business Research, 5(10), pp. 19-28.

Kritsana, T. (2007). Selected factors and willingness of resignation of professional nurses in Maharaj Nakorn Chiang Mai Hospital. Master Thesis (Nursing Science), Nursing Administration College, Chiang Mai University, Thailand. 
Boonpermrasri, T. (2009). Interpersonal Relationships Affecting the Resignation of Personnel: A Case Study of Dhurakijpundit University. Master of Arts thesis (Industrial and Organizational Psychology), College King Mongkut's University of Technology, North Bangkok.

Paper submitted

Paper accepted for publishing

Paper published online
23 March 2018

19 May 2018

31 July 2018 